\title{
Novel mutations of TCOF1 gene in European patients with treacher Collins syndrome
}

\author{
Chiara Conte ${ }^{1}$, Maria Rosaria D'Apice ${ }^{1,2^{*}}$, Fabrizio Rinaldi ${ }^{2}$, Stefano Gambardella ${ }^{3}$, Federica Sangiuolo ${ }^{1,2}$ and \\ Giuseppe Novelli, ${ }^{1,2}$
}

\begin{abstract}
Background: Treacher Collins syndrome (TCS) is one of the most severe autosomal dominant congenital disorders of craniofacial development and shows variable phenotypic expression. TCS is extremely rare, occurring with an incidence of 1 in 50.000 live births. The TCS distinguishing characteristics are represented by down slanting palpebral fissures, coloboma of the eyelid, micrognathia, microtia and other deformity of the ears, hypoplastic zygomatic arches, and macrostomia. Conductive hearing loss and cleft palate are often present. TCS results from mutations in the TCOF1 gene located on chromosome 5, which encodes a serine/alanine-rich nucleolar phosphoprotein called Treacle. However, alterations in the TCOF1 gene have been implicated in only $81-93 \%$ of TCS cases.

Methods: In this study, the entire coding regions of the TCOF1 gene, including newly described exons $6 \mathrm{~A}$ and 16A, were sequenced in 46 unrelated subjects suspected of TCS clinical indication.

Results: Fifteen mutations were reported, including twelve novel and three already described in 14 sporadic patients and in 3 familial cases. Moreover, seven novel polymorphisms were also described. Most of the mutations characterised were microdeletions spanning one or more nucleotides, in addition to an insertion of one nucleotide in exon 18 and a stop mutation. The deletions and the insertion described cause a premature termination of translation, resulting in a truncated protein.
\end{abstract}

Conclusion: This study confirms that almost all the TCOF1 pathogenic mutations fall in the coding region and lead to an aberrant protein.

Keywords: Treacher Collins syndrome, TCOF1 mutations, microdeletions, microinsertions

\section{Background}

Treacher Collins syndrome (TCS; OMIM \#154500) is an autosomal dominant disorder that affects the craniofacial development during early embryogenesis [1]. TCS is characterized by bilaterally symmetric features, including downward slanting palpebral fissures and colobomata of the lower eyelids, hypoplasia of the midfacial bones, cleft palate, and abnormal development of the external/ middle ear that often leads to conductive hearing loss [2-4]. TCS occurs with an incidence of $1 / 50.000$ and more than $60 \%$ of TCS cases has no previous family history and arises as the result of de novo mutations [5]. The syndrome is caused by mutations in the TCOF1 gene (OMIM \#606847), which encodes the nucleolar

\footnotetext{
* Correspondence: d.apice@med.uniroma2.it

${ }^{1}$ Fondazione Policlinico di Tor Vergata, Rome, Italy

Full list of author information is available at the end of the article
}

phosphoprotein Treacle that may serve as a link between rDNA gene transcription and pre-rRNA processing [6]. Recently, Dauwerse et al. detected mutations in genes encoding subunits of RNA polymerases I and III (POLR1C and POLR1D) in Treacher Collins patients [7].

Thus far, most of the 200 disease-causing mutations described are deletions, insertions and nonsense, distributed along 28 exons [8]. Two additional exons have been reported: exon $6 \mathrm{~A}$, included in the most common isoform, and exon 16A, included in a minor isoform [9]. The mutations observed in TCS are predominantly sporadic, and the vast majority results in the introduction of a premature termination codon that can lead to the truncation of protein or to nonsense-mediated mRNA decay $[10,11]$. This suggests in the developmental anomalies result from haploinsufficiency of TCOF1.
C Biomed Central

() 2011 Conte et al; licensee BioMed Central Ltd. This is an Open Access article distributed under the terms of the Creative Commons Attribution License (http://creativecommons.org/licenses/by/2.0), which permits unrestricted use, distribution, and reproduction in any medium, provided the original work is properly cited. 
Penetrance of the genetic mutations underlying TCS is thought to be very high; however, extreme inter- and intra- familial phenotypic variation is reported [12].

In the present study, we screened 46 patients with a clinical diagnosis of TCS, by sequencing the entire TCOF1 coding sequence together with the splice junctions. As result, 12 novel and 3 already reported mutations were characterised together with 7 novel and 13 known polymorphisms.

\section{Methods}

\section{Patients}

46 patients with a clinical diagnosis of TCS were recruited through several European Medical Institutes since 2002. In particular, the patients were evaluated at the University of Torino, Napoli, Rome Tor Vergata and "La Sapienza", University of Aquila, Ospedali Galliera of Genova, IRCCS Casa Sollievo della Sofferenza at San Giovanni Rotondo, Pediatric Department of SS. Pietro e Paolo Hospital at Borgosesia, Pediatric Department of the Bolzano Hospital, "Gaetano Rummo" Hospital at Benevento, Clinica Mangiagalli at Milano, S. Pietro Hospital at Rome, IRCCS “Ass. Oasi Maria SS" at Troina (Italy), GENDIA lab (Antwerp, Belgium), Egas Moniz Hospital (Lisbon, Portugal), Centre Hospitalier Universitaire de Rennes (France). Three patients have one parent with similar TCS features, while the other 43 cases haven't a family history. The major clinical features of TCS were recognized in all patients. After informed consent was obtained from patients or their families, blood samples were collected.

\section{Mutational analysis}

Genomic DNA was obtained from peripheral blood samples using EZ1 DNA Blood $200 \mu$ l purification kit (Qiagen, GmbH, Germany). Coding regions and intron/exon boundaries of the TCOF1 gene were amplified in 28 reactions using specific primers [13]. For exons 6A, 10, 16A, 24 , and 25 specific primers were self designed (Table 1 ).

PCR amplification was performed in a $25 \mu$ l reaction volume containing $2.5 \mathrm{U}$ AmpliTaq Gold ${ }^{\mathrm{TM}}$ DNA polymerase (Applied Biosystems, Foster City, CA), 1X reaction buffer $(10 \mathrm{mM}$ Tris $\mathrm{HCl} \mathrm{pH}$ 8.3, $50 \mathrm{mM} \mathrm{KCl}, 2.5$ $\mathrm{mM} \mathrm{MgCl}_{2}$ ), $200 \mu \mathrm{M}$ of each deoxyribonucleoside

Table 1 Primers self-designed for TCOF1 gene amplification and sequencing

\begin{tabular}{lll}
\hline & FORWARD & REVERSE \\
\hline Ex 6A & TTTATCAACTGCTGAAGCCCC & ATAGTCCTCCCTCTCCCCAAC \\
\hline Ex 10 & CTGAACCTAGAGCCCTGTGGG & AGACAGAGTCCCAGAGTGAGG \\
\hline Ex 16A & TGGAAACCAGAGTGCCTGAG & TGATCCTGCAGCATCTGCAG \\
\hline Ex 24 & GCACCTCCCAACATTGAC & GAACCAGGTCTGGGTGT \\
\hline Ex 25 & TCACTAGTCCTCAGGAGGT & CTGCCTGGCTCTCTGGGA \\
\hline
\end{tabular}

triphosphate (dNTPs) and $0.2 \mathrm{mM}$ each of primers using a PTC 100 thermocycler (MJ Research, Inc. Waltham, MA, USA).

A 10-minute denaturation step at $94^{\circ} \mathrm{C}$ was followed by 30 cycles at $94^{\circ} \mathrm{C}$ for 30 seconds, annealing temperature was performed, for each primer, 30 seconds at $52.5-62^{\circ} \mathrm{C}$, and extending for $30 \mathrm{sec}$ at $72^{\circ} \mathrm{C}$; the reaction was completed by a final extension for $7 \mathrm{~min}$ utes at $72^{\circ} \mathrm{C}$.

PCR products were purified by digestion with Antartic Phosphatase and Exonuclease I (New England BioLabs Inc.) and were sequenced in both directions using the Applied Biosystem Big Dye Terminator v3.1 Cycle sequencing kit.

New mutations were not found in 100 normal chromosomes by sequencing.

\section{Nucleotide and Aminoacid numbering}

All mutations were named considering the genomic reference [NT_029289] and the cDNA that corresponds to the major treacle isoform [NM_001135243.1] [14]. Mutation nomenclature is based on HGVS nomenclature guidelines [http://www.hgvs.org/mutnomen] [15].

\section{In silico tools}

The splice predictor software program, NNSplice version 0.9 [http://www.fruitfly.org/seq_tools/splice.html], was used for an initial approach to novel variant (c. IVS16A-30G $\rightarrow$ A) suspected of causing aberrant RNA processing of the TCOF1 gene. The ESE finder 2.0 program [http://rulai.cshl.edu/tools/ESE2/] was used to predict hypothetical splicing enhancer in mutated c. IVS16A-30G $\rightarrow$ A sequence.

\section{Results}

The TCOF1 gene analysis was carried out on the 46 TCS European patients by direct sequencing of 28 PCR genomic fragments encompassing the complete coding sequence and splice sites. We detected 15 different TCOF 1 mutations in 17 patients (Table 2 Figure 1 ), 12 new and 3 already described.

Considering the already known mutations, the 5-bp deletion, c.4366_4370delGAAAA, in exon 24 (Figure $1 \mathrm{~A})$, was the most frequent mutation observed in this study $(3 / 17,17 \%)$ (Patient TCS 15,16 and 17). In the same exon (patient TCS 14), we identified the already known frameshift mutation c.4359_4363delAAAAA (Figure 1B). Both the mutations identified fall within the TCOF1 mutation hot spot rich in 18 Lysine residues. Other microdeletions have already been described in this region $[8,11,16-18]$.

The other known mutation is a 2 bp deletion, c.1639_1640delAG (patient TCS 4), localized in exon 10 (Figure 1C) $[8,13]$. 
Table 2 Pathogenic mutations in TCS patients

\begin{tabular}{|c|c|c|c|c|c|c|}
\hline PATIENT & $\begin{array}{l}\text { GEOGRAPHIC } \\
\text { ORIGIN }\end{array}$ & EXON & CDNA MAJOR ISOFORM MUTATION & PROTEIN MUTATION & OCCURRENCE & REFERENCE \\
\hline TCS 1 & caucasian & 3 & c.303_304delCA & p.A101Afsx73 & Sporadic & In this study \\
\hline TCS 2 & caucasian & 5 & c.519delT & p.T173Tfs $\times 46$ & Sporadic & In this study \\
\hline TCS 3 & caucasian & 6 & c.599delG & p.S200Tfsx19 & Familial & In this study \\
\hline TCS 4 & caucasian & 10 & c.1639_1640delAG & p.S547Qfs x2 & Sporadic & [13] \\
\hline TCS 5 & caucasian & 10 & c.1581delG & p.G587Gfsx69 & Sporadic & In this study \\
\hline TCS 6 & caucasian & 12 & c.1973delC & p.P658Lfsx53 & Sporadic & In this study \\
\hline TCS 7 & caucasian & 13 & c.2285_2286delCT & p.S762fs & Sporadic & In this study \\
\hline TCS 8 & caucasian & 15 & c.2626_2627delGA & p.D876Qfs x2 & Sporadic & In this study \\
\hline TCS 9 & caucasian & 16 & c.2831delA & p.E944Efsx6 & Sporadic & In this study \\
\hline TCS 10 & caucasian & 18 & c.3118_3119dupG & p.A1040Gfx47 & Familial & In this study \\
\hline TCS 11 & caucasian & 20 & c.3456_63delTTCTTCAG & p.S1152Rfs x3 & Sporadic & In this study \\
\hline TCS 12 & caucasian & 22 & c.3700_3704delACTCT & p.T1234Gfsx5 & Sporadic & In this study \\
\hline TCS 13 & caucasian & $23 B$ & C. $4331 \mathrm{C}>\mathrm{T}$ & p.Q1411X & Sporadic & In this study \\
\hline TCS 14 & caucasian & 24 & c.4359_4363delAAAAA & p.E1453Efsx16 & Sporadic & {$[17]$} \\
\hline $\begin{array}{l}\text { TCS } 15 \\
\text { TCS } 16 \\
\text { TCS } 17\end{array}$ & caucasian & 24 & c.4366_4370delGAAAA & p.E1456Efsx13 & $\begin{array}{l}\text { Familial } \\
\text { Sporadic } \\
\text { Sporadic }\end{array}$ & {$[17]$} \\
\hline
\end{tabular}

The cDNA major isoform (including exon 6A, but without exon 16A) was deposited in GenBank with accession number AY460334[14].

For the CDNA sequence, nucleotide +1 is the $A$ of the ATG-translation initiation codon.

A total of 12 novel disease-causative mutations were found in 2 familial cases and in 10 sporadic TCS patients. These consist of 10 microdeletions (sized 1/15 nucleotides), one single-base duplication, and one nonsense mutation. All deletions and insertion cause a frameshift and produce a truncated protein.

The first reported pathogenic microdeletion was a c.519delT in exon 5 (patient TCS 2) (Figure 1D) leading to formation of a stop codon 46 aminoacids later. This alteration was not found in the patient's parents. Patient TCS 5 was found to bear a de novo truncating mutation, c.1581delG, in exon 10 (Figure 1E) that introduces a premature stop codon 69 aminoacids later.

Two alterations were identified in exons 15 and 16, that encode repetitive motifs. The former, c.2626_2627delGA in exon 15 (Figure 1F), was identified in patient TCS 8 and causes the formation of a stop codon two aminoacids later. The latter, c.2831delA (Figure 1G), identified in the exon 16 of patient TCS 9 , causes a frameshift.

Another proband (TCS 12) was heterozygous for the de novo c.3700_3704delACTCT mutation in exon 22 (Figure 1H).

The sequence analysis of a DNA sample obtained from patient TCS 10 identified the c.3118_3119dupG mutation in exon 18 (Figure 1I). Analysis of the relatives indicated that this duplication was also present in the affected father and brother.

Two more TCOF1 variations were found in patient TCS 7. The first one was a single base sostitution,
c.2924C > T, in exon 17, determining the aminoacidic change p.P975L. The other one was a 2 bp deletion, c.2285_2286delCT in exon 13 (Figure 1J), wich results in a frameshift and premature stop codon. Neither abnormality was found in 140 and 100 healty chromosomes, respectively, indicating that they were not common polymorphisms.

Analysis of TCS 7's normal parents DNA showed the mother was a carrier of c. $2924 \mathrm{C}>\mathrm{T}$. Neither of parents showed the 2 bp deletion. Thus, it was indicated that the 2 bp deletion, disrupting protein translation, is probably the causative mutation.

In the TCS 11 patient, a truncating mutation of 8 bases c.3456_3463delTTCTTCAG (Figure 1K) was found in exon 20, causing a frameshift resulting in a stop codon four codons later. The same kind of mutation was found in TCS 6 patient in exon 12. A microdeletion of one single base c.1973delC (Figure 1L) with a stop codon 52 codons later.

In patient TCS 13 a nonsense mutation c. $4231 \mathrm{C}>\mathrm{T}$ (Figure $1 \mathrm{M}$ ) was found. This pathogenetic variation occurred in exon 23B causing a stop codon (p.Q1411X). In patient TCS 1 a small deletion was found. It was a truncating mutation of the last 2 nucleotides of exon 3, c.303_304delCA (Figure 1N), causing a stop codon 73 codons later. Actually, the deletion involves the first 13 nucleotides of intron 3 (IVS3+13delGTAAGAGCCTTGC), too.

Finally, we detected a one bp deletion c.599delG in patient TCS 3 (Figure 1O). It was a familial case, as we 


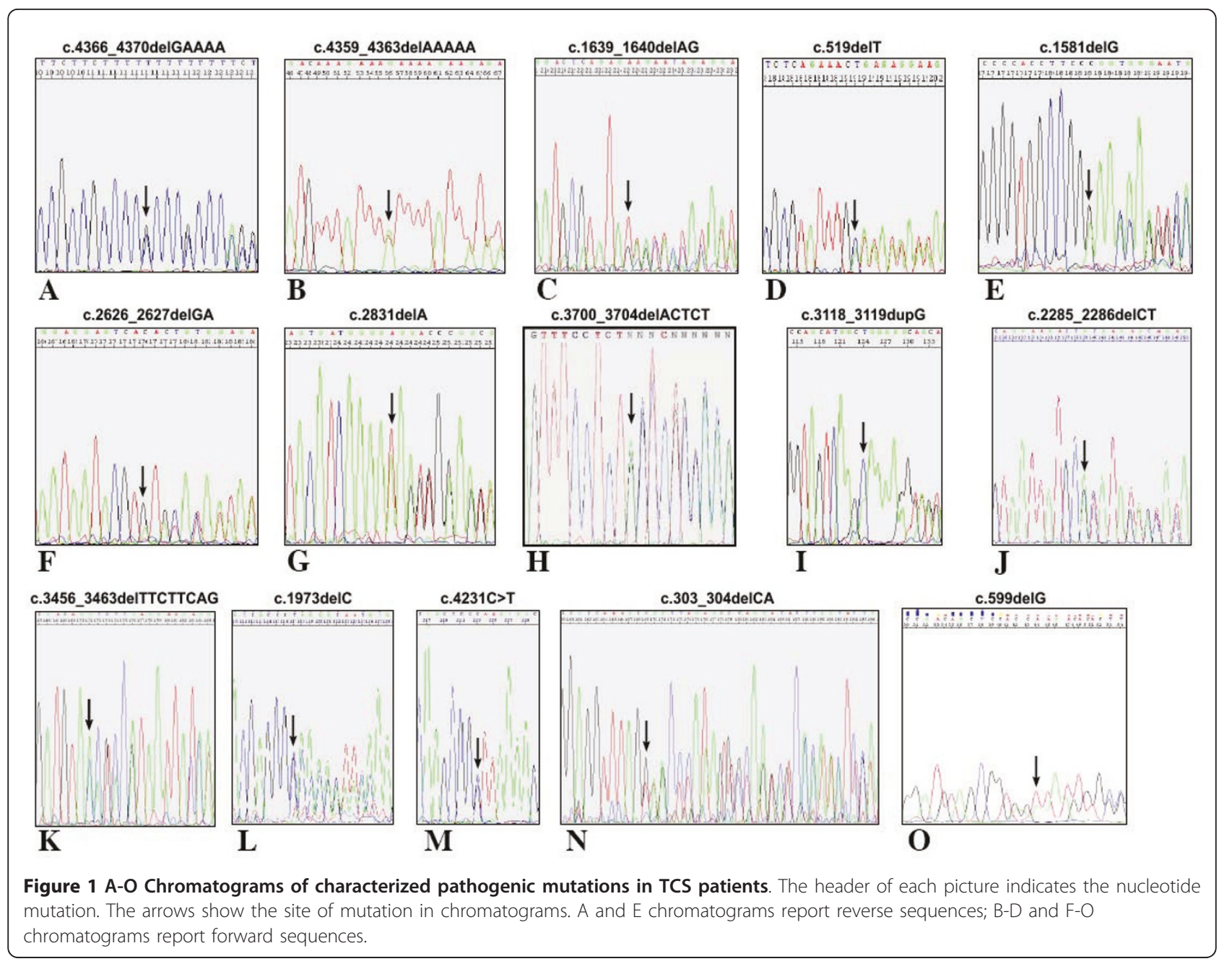

confirmed the mutation in proband's son and daughter. It was located in exon 6 and it caused a stop codon 19 codons later.

In 29 patients, with apparently TCS phenotype, no pathogenic mutations have been identified after screening of the whole coding region of the gene. However these patients present clinical features of the syndrome. All these cases are isolated.

A large number of TCOF1 polymorphisms were detected. Thirteen of these were already published and 7 are novel (Table 3). Twelve were silent or missense variation and 8 occur in intronic regions. All novel polymorphisms were present in controls in different percentages.

Patient TCS 21 had a single base substitution c.2859$30 \mathrm{G}>\mathrm{A}$ in exon 16. This substitution wasn't identified in 150 healthy chromosomes; therefore, this variation could be a novel splicing mutation in the TCOF1 gene. Computer simulation studies were performed to evaluate the role of this variation in hypothetical splicing enhancer or splice site prediction, and we deduced that the mutated sequence determines a loss of SF2/ASF and Srp55 and a gain of SRp40 binding sites, but the same splice site strength score was 0.89 , similar to wild type sequence, according to ESE finder and NNSplice programs, respectively.

\section{Discussion}

In this study, we report the screening of entire TCOF1 coding region and the identification of a spectrum of 3 known mutations, 12 novel pathogenetic mutations and 7 novel polymorphisms by direct sequencing. In all familial cases, we identified the TCOF1 mutation in one parent with similar TCS features. Of the 43 analyzed sporadic cases, 14 had arisen as the result of a de novo mutations in the TCOF1 gene. The sensitivity of sequencing analysis of TCOF1 gene on our patients was $37 \%$ (17/46). The remaining 29 TCS patients, negative to the TCOF1 screening, have to be clinically revaluated. In this regard, we recommend a clinical revaluation using 
Table 3 Polymorphisms in TCS patients

\begin{tabular}{|c|c|c|c|c|c|}
\hline PATIENT & LOCATION & $\begin{array}{l}\text { CDNA MAJOR } \\
\text { ISOFORM } \\
\text { POLYMORPHISM }\end{array}$ & $\begin{array}{l}\text { AMINOACID } \\
\text { CHANGE }\end{array}$ & $\begin{array}{c}\text { ALLELE } \\
\text { FREQUENCIES } \\
\text { IN CONTROLS }\end{array}$ & REFERENCE \\
\hline TCS 8, TCS 18 & 5'UTR & $5^{\prime} U T R-41 G>T$ & None & 0.82 & In this study \\
\hline TCS 18 & Intron 6 & c.. $639+32 C>G$ & None & 0.02 & {$[11]$} \\
\hline TCS 19 & Exon 7 & C.1347T > C & p.P439L & 0.01 & [13] \\
\hline TCS 6, TCS 11 & Exon 10 & c.1578 T > C & p.P526P & 0.77 & [13] \\
\hline TCS 1, TCS 6, TCS 17, TCS 19 & Exon 11 & c.1761G > T & p.G587G & 0.10 & [11] \\
\hline TCS 17, TCS 19, TCS 20 & Exon 11 & c. $1842 A>G$ & p.S614S & 0.52 & [13] \\
\hline TCS 10 & Exon 12 & $1837 G>C$ & p.A588P & 0.31 & In this study \\
\hline TCS 10, TCS 10.1, TCS 10.3, TCS 11, TCS 20 & Exon 12 & c. $1993 C>$ G & p.A665P & 0.21 & $\begin{array}{l}\text { International HapMap } \\
\text { project }\end{array}$ \\
\hline TCS10, TCS 11, TCS 20 & Intron 15 & c.2659-28delTCTC & None & 0.15 & In this study \\
\hline TCS 13 & Exon16 & c. $2660 \mathrm{C}>\mathrm{T}$ & p.A887V & 0.82 & [13] \\
\hline TCS 19 & Exon 16 & c.2765 C > T & p.S992L & 0.01 & [13] \\
\hline TCS 21 & Intron 16 & c.2859-30G > A & None & 0.0 & In this study \\
\hline TCS 11, TCS 20 & Intron 16A & c. $2859+3444 C>T$ & None & 0.05 & In this study \\
\hline TCS 7, Mother carrier & Exon 17 & c. $2924 C>T$ & p.P975L & 0.0 & In this study \\
\hline TCS 22 & Intron 19 & $c .3197+66 C>T$ & None & 1.0 & $\begin{array}{l}\text { International HapMap } \\
\text { project }\end{array}$ \\
\hline TCS 13, TCS 19 & Intron 20 & c. $3517-34 G>A$ & None & 0.1 & In this study \\
\hline TCS 13, TCS 14, TCS19, TCS 23, TCS 24, TCS 25 & Exon 21 & C.3527C > G & p.P1176R & 0.16 & [11] \\
\hline TCS 1, TCS 13, TCS 19 & Intron 21 & c.3370-3C > T & None & 1.0 & {$[8]$} \\
\hline $\begin{array}{c}\text { TCS 6, TCS 22, TCS 26, TCS 27, TCS 28, TCS 29, TCS } 30, \\
\text { TCS } 31, \text { TCS } 32\end{array}$ & Exon 23B & C.4169C > T & p.A1390V & 0.24 & [11] \\
\hline TCS 23, TCS 32 & Exon 23B & C. $4292 G>C$ & p.G1431A & 0.03 & [11] \\
\hline
\end{tabular}

The URL for International HapMap project is http://hapmap.ncbi.nlm.nih.gov/

craniofacial radiographs, extremely useful in detecting zygomatic hypoplasia as a clinical feature of TCS patients [19]. On the other hand, the differential diagnosis is necessary. In fact, Nager and Miller syndrome exhibits phenotypic overlap with TCS. Moreover, mutations in genes encoding subunits of RNA polymerases I and III (POLR1C and POLR1D) cause TCS, too [7]. We are considering to perform the screening of POLR1C and POLR1D genes in our negatives TCOF1 patients.

The TCOF1 gene mutations include missense, nonsense, small deletions and duplications. In particular, the most common classes of TCOF1 alleles are small deletions $(60 \%)$ and duplications (25\%) resulting in frameshifts [10]. According to literature data, 76.5\% (13/ 17) of our characterised mutations are microdeletions and $6 \%(1 / 17)$ are duplications. Though it has been suggested that five exons $(10,15,16,23$ and 24), are defined as a hot spot region of the TCOF1 gene mutations [14], a distribution of pathogenic variations along all the gene was reported by different authors. We confirmed exon 24 as hot spot of the TCOF1 gene as we described the major number of mutations in the exon (Table 2 Figure 1). The c.4366_4370delGAAAA is the most frequent mutation as we found it in three of 16 affected patients. This is probably due to the high repetition of adenines (60\% of exon) making exon 24 region prones to polymerase slippage in DNA replication [14]. Moreover, the high complexity of this exon make it difficult to give the right nomenclature to the identified sequence variations. It is therefore mandatory to sequence exon 24 in both directions. Also in this study exons 10,15 , and 16 were revealed as pathogenic gene regions. Finally, three mutations were found in rarely affected sequences.

Two more TCOF1 variations were found in patient TCAR. The presence of two possible TCOF1 mutations in the same patient has been reported in a paper by Fujioka $\mathrm{H}$ et al. [20]. In this case, familiar analysis is requested to predict which is the benign and which is the pathological variation in TCS.

All patients, and in particular patients with typical TCS features but negative TCOF1 screening, were analyzed for the two alternatively spliced in-frame exons (6A and 16A) and no mutations were found.

\section{Conclusion}

In this work, the observation of affected features, combined with a molecular analysis, is sufficient to perform a correct TCS diagnosis in $35 \%$ of cases. This is the phenotypic variability of TCS. 


\section{Ackowledgements}

We are thankful to Drs. Silengo M, David V, Blayau M, Guala A, Dalla Monica M, Scarano G, Bengala M, Frontali M, Willems P, Novelli A, Sorrentino, Calcagno G, Lourenço MT, Dagna Bricarelli F, Faravelli F, Tozzi MC, Ligas C, Zelante L, Castellan C, Stanzial F, Lalatta F, and Avola E for referring their patients for evaluation to us. We also thank Gigante L, Longo G, Nuovo S for help with mutation screening.

\section{Author details}

${ }^{1}$ Fondazione Policlinico di Tor Vergata, Rome, Italy. ${ }^{2}$ Dipartimento di Biopatologia e Diagnostica per Immagini, Università di Roma Tor Vergata, Rome, Italy. ${ }^{3}$ Fondazione Livio Patrizi, Rome, Italy.

\section{Authors' contributions}

CC, MRD decided the study; CC, FR collected blood samples and performed the experiments; SG, FS wrote the paper, GN coordinated this study. All authors read and approved the final manuscript.

\section{Competing interests}

The authors declare that they have no competing interests.

Received: 1 March 2011 Accepted: 27 September 2011

Published: 27 September 2011

\section{References}

1. Gorlin RJ, Cohen MM, Levin LS: Syndromes of the head and neck. Oxford University Press, 1990, Oxford, UK

2. Treacher Collins E: Case with symmetrical congenital notches in the outer part of each lower lid and defective development of the malar bones. Trans Opthalmol Soc UK 1900, 20:90.

3. Franceschetti A, Klein D: The mandibulofacial dysostosis; a new hereditary syndrome. Acta Ophthalmol 1949, 27:143-224

4. Phelps PD, Poswillo D, Lloyd GA: The ear deformities in mandibulofacial dysostosis (Treacher Collins syndrome). Clin Otolaryngol Allied Sci 1981 6:15-28.

5. Splendore A, Jabs EW, Felix TM, Passos-Bueno MR: Parental origin of mutations in sporadic cases of Treacher Collins syndrome. Eur J Hum Genet 2003, 11:718-722.

6. The Treacher Collins Syndrome Collaborative Group: Positional cloning of a gene involved in the pathogenesis of Treacher Collins syndrome. Nat Genet 1996, 12:130-136.

7. Dauwerse JG, Dixon J, Seland S, Ruivenkamp CA, van Haeringen A, Hoefsloot LH, Peters DJ, Boers AC, Daumer-Haas C, Maiwald R, Zweier C, Kerr B, Cobo AM, Toral JF, Hoogeboom AJ, Lohmann DR, Hehr U, Dixon MJ, Breuning MH, Wieczorek D: Mutations in genes encoding subunits of RNA polymerases I and III cause Treacher Collins syndrome. Nat Genet 2011, 43:20-22.

8. Splendore A, Jabs EW, Passos-Bueno MR: Screening of TCOF1 in patients from different populations: confirmation of mutational hot spots and identification of a novel missense mutation that suggests an important functional domain in the protein treacle. J Med Genet 2002, 39:493-495.

9. So BR, Gonzales B, Henning D, Dixon J, Dixon MJ, Valdez BC: Another face of the Treacher Collins syndrome (TCOF1) gene: identification of additional exons. Gene 2004, 328:49-57.

10. Dixon MJ, Marres HA, Edwards SJ, Dixon J, Cremers CW: Treacher Collins syndrome: correlation between clinical and genetic linkage studies. Clin Dysmorphol Apr 1994, 3:96-103.

11. Splendore A, Silva EO, Alonso LG, Richieri-Costa A, Alonso N, Rosa A, Carakushanky G, Cavalcanti DP, Brunoni D, Passos-Bueno MR: High mutation detection rate in TCOF1 among Treacher Collins syndrome patients reveals clustering of mutations and 16 novel pathogenic changes. Hum Mutat 2000, 16:315-322.

12. Dixon J, Ellis I, Bottani A, Temple K, Dixon MJ: Identification of mutations in TCOF1: use of molecular analysis in the pre- and postnatal diagnosis of Treacher Collins syndrome. Am J Med Genet A 2004, 127A:244-248.

13. Wise CA, Chiang LC, Paznekas WA, Sharma M, Musy MM, Ashley JA, Lovett M, Jabs EW: TCOF1 gene encodes a putative nucleolar phosphoprotein that exhibits mutations in Treacher Collins Syndrome throughout its coding region. Proc Natl Acad Sci USA 1997, 94:3110-3115.

14. Splendore A, Fanganiello RD, Masotti C, Morganti LS, Passos-Bueno MR: TCOF1 mutation database: novel mutation in the alternatively spliced exon $6 \mathrm{~A}$ and update in mutation nomenclature. Hum Mutat 2005, 25:429-434

15. den Dunnen JT, Antonarakis SE: Mutation nomenclature extensions and suggestions to describe complex mutations: a discussion. Hum Mutat 2000, 15:7-12.

16. Teber OA, Gillessen-Kaesbach G, Fischer S, Böhringer S, Albrecht B, Albert A, Arslan-Kirchner M, Haan E, Hagedorn-Greiwe M, Hammans C, Henn W, Hinkel GK, König R, Kunstmann E, Kunze J, Neumann LM, Prott EC, Rauch A, Rott HD, Seidel H, Spranger S, Sprengel M, Zoll B, Lohmann DR, Wieczorek D: Genotyping in 46 patients with tentative diagnosis of Treacher Collins syndrome revealed unexpected phenotypic variation. Eur J Hum Genet 2004, 12:879-890.

17. Edwards SJ, Gladwin AJ, Dixon MJ: The mutational spectrum in Treacher Collins syndrome reveals a predominance of mutations that create a premature-termination codon. Am J Hum Genet 1997, 60:515-524.

18. Ellis PE, Dawson M, Dixon MJ: Mutation testing in Treacher Collins Syndrome. J Orthod 2002, 29:293-297.

19. Marres HA, Cremers CW, Dixon MJ, Huygen PL, Joosten FB: The Treacher Collins syndrome: correlation between clinical and genetic linkage study on two pedigrees. Arch Otolaryngol Head Neck Surg 1995, 121:509-514.

20. Fujioka H, Ariga T, Horiuchi K, Ishikiriyama S, Oyama K, Otsu M, Kawashima K, Yamamoto Y, Sugihara T, Sakiyama Y: Detection of a novel silent deletion, a missense mutation and a nonsense mutation in TCOF1. Pediatr Int 2008, , 50: 806-809.

\section{Pre-publication history}

The pre-publication history for this paper can be accessed here: http://www.biomedcentral.com/1471-2350/12/125/prepub

doi:10.1186/1471-2350-12-125

Cite this article as: Conte et al:: Novel mutations of TCOF1 gene in European patients with treacher Collins syndrome. BMC Medical Genetics 2011 12:125

\section{Submit your next manuscript to BioMed Central and take full advantage of:}

- Convenient online submission

- Thorough peer review

- No space constraints or color figure charges

- Immediate publication on acceptance

- Inclusion in PubMed, CAS, Scopus and Google Scholar

- Research which is freely available for redistribution

Submit your manuscript at www.biomedcentral.com/submit
C Biomed Central 